\title{
UPAYA PENINGKATAN MUTU PENDIDIKAN TINGGI SERTA IMPLIKASINYA TERHADAP TUGAS DAN PERAN DOSEN
}

\author{
Rizkan Syahbuddin \\ IAIN Bengkulu
}

\begin{abstract}
National development that lasts all the time, then the development of higher education is still prioritized by the government to continue to grow, including the role and duties of lecturers. Strategy setting is part of long-term development. The goal is in the most appropriate way in the future to be able. Improving the quality of higher education can not be separated from the quality of human resources owned. Therefore, improving the quality of the behavior and behavior of lecturers as teachers through education channels and effective training programs in their work is needed. With qualified human resources, it is expected that higher education will become an institution capable of effectively facing the challenges of the future.
\end{abstract}

Keywords : Quality of Education, Lecturer Duty, Role of Lecturer

Abstrak: Pembangunan nasional yang berlangsung sepanjang waktu, maka pengembangan pendidikan tinggi masih diprioritaskan oleh pemerintah untuk terus tumbuh, termasuk peran dan tugas dosen. Pengaturan strategi adalah bagian dari pembangunan jangka panjang. Tujuannya adalah cara yang paling tepat di masa depan untuk bisa. Meningkatkan kualitas pendidikan tinggi tidak terlepas dari kualitas sumber daya manusia yang dimiliki. Oleh karena itu, meningkatkan kualitas perilaku dan perilaku dosen sebagai guru melalui saluran pendidikan dan program pelatihan yang efektif dalam pekerjaan mereka sangat diperlukan. Dengan sumber daya manusia yang berkualitas, diharapkan pendidikan tinggi akan menjadi lembaga yang mampu menghadapi tantangan masa depan secara efektif.

Kata Kunci: Kualitas Pendidikan, Tugas Dosen, Peran Dosen

\section{Pendahuluan}

Reformasi pendidikan merupakan respon terhadap perkembangan tuntutan global sebagai suatu upaya untuk mengadaptasikan sistem pendidikan yang mampu mengembangkan sumber daya manusia untuk memenuhi tuntutan zaman yang sedang berkembang. Standar Mutu Pendidikan Nasional dicerminkan oleh kompetensi lulusan yang dipengaruhi oleh kualitas proses dan isi pendidikan. Pencapaian kompetensi lulusan yang memenuhi standar harus didukung oleh isi dan proses pendidikan yang juga memenuhi standar. ${ }^{1}$

'http://bsnp-indonesia.org/standar-nasional-pendidikan/ pada tanggal 25 September 2017
.Diakses
Pendidikan merupakan hal yang sangat penting untuk menjamin perkembangan dan kelangsungan kehidupan bangsa. Pendidikan adalah usaha sadar untuk menyiapkan peserta didik melalui kegiatan bimbingan, pengajaran, dan/atau latihan bagi peranannya di masa yang akan datang. Setiap warga negara Indonesia berhak memperoleh pendidikan pada tahap manapun dalam perjalanan hidupnya. Pendidikan dapat diperoleh baik melalui jalur pendidikan sekolah maupun jalur pendidikan luar sekolah. Melalui pendidikan, manusia Indonesia diharapkan menjadi individu yang mempunyai kemampuan dan ketrampilan untuk secara mandiri meningkatkan taraf hidup lahir batin, dan meningkatkan peranannya sebagai pribadi, pegawai atau karyawan, warga masyarakat, warga negara dan 
makhluk Tuhan.

Penetapan strategi merupakan bagian terpenting untuk pengembangan Pendidikan Tinggi. Penetapan strategi tersebut didasarkan atas suatu penelaahan sistematis tentang sistem yang meliputi (1) wawasan, (2) misi untuk mewujudkan wawasan, (3) keadaan intern dan ekstern yang berpengaruh terhadap pencapaian misi. (4) identifikasi masalah utama yang harus ditangani untuk memperbaiki keadaan, dan (5) rencana perbaikan. Strategi pengembangan pendidikan tinggi meliputi telaah strategis, paradigma penataan sistem pendidikan tinggi, peningkatan relevansi dan mutu, serta pemerataan pendidikan tinggi. ${ }^{2}$

\section{Telaah Strategis}

Telaah strategis diawali dengan menggambarkan keadaan Sistem Pendidikan Tinggi yang diinginkan pada masa yang akan datang. Gambaran tersebut dinyatakan sebagai wawasan jangka panjang yang digunakan sebagai acuan umum perumusan misi sistem untuk mencapai keadaan yang diinginkan. Langkah selanjutnya adalah membuat daftar tentang kekuatan dan kelemahan intern sistem, serta peluang dan ancaman dari lingkungan ekstern sistem yang berpengaruh terhadap pencapaian misi sistem.

Uraian tentang semua unsur yang mempengaruhi pencapaian misi sistem kemudian di analisis untuk menemukenali beberapa masalah besar sistem. Langkah ini dinamakan analisis kekuatankelemahan-peluang-ancaman, disingkat Analisis KKPK atau (SWOT - Analisis ).

Langkah terakhir adalah menyusun suatu program perbaikan keadaan sistem dalam suatu struktur program yang memberikan gambaran komprehensif untuk merencanakan, mengendalikan implementasi, dan membuat evaluasi tentang pelaksanaannya.

Isi dari telaah strategis tersebut adalah:

a. Wawasan Jangka Panjang.

b. Misi Sistem Pendidikan Tinggi.

c. Keadaan Internal Sistem dan Lingkup Ekternal yang Mempengaruhi Pencapaian Misi Sistem Seperti :

1. kekuatan internal sistem.

${ }^{2}$ Soehendro, Bambang, Kerangka Pengembangan Pendidikan Tingg Jangka Panjang 1996-2005. Jakarta : Depdikbud, Dirjen Dikti, 1996), h. 78
2. kelemahan internal sistem.

3. Peluang dari lingkungan eksternal.

4. lima ancaman dari lingkungan eksternal.

d. Identifikasi Masalah utama.

e. Rencana Pengembangan.

\section{Paradigma Penataan Sistem Pendidikan Tinggi}

Apapun yang akan dinyatakan sebagai tujuan pendidikan, fungsi dasarnya di setiap masyarakat adalah sosialaisasi, dalam arti menyiapkan generasi muda untuk menghadapi dan mengatasi masalah-masalah pembangunan masyarakat di kemudian hari. Masyarakat Indonesia tidak terlepas dari masalah-masalah yang dihadapi oleh masyarakat dunia,yaitu pergaulan antar bangsa akan akan dilandasi oleh mekanisme pasar yang disertai mobilitas barang dan jasa secara global.

Untuk menghadapi hal tersebut, Direktorat Jenderal Pendidikan Tinggi telah menyatakan bahwa salah satu tujuan utama Pendidikan Tinggi untuk Pelita VI dan menyongsong tonggak-tonggak waktu tahun 2005 dan 2020 adalah penataan sistem pendidikan agar lebih sesuai dengan kebutuhan masyarakat dan pembangunan.

Penataan Sistem Pendidikan Tinggi didasarkan atas 5 komponen. Kelima komponen tersebut adalah kualitas, otonomi, akuntabilitas, akreditasi dan evaluasi yang didapat digunakan sebagai acuan dasar atau Paradigma Penataan Sistem Pendidikan Tinggi yang meliputi :

1) Hasil dan kinerja perguruan tinggi harus selalu mengacu pada kualitas yang berkelanjutan.

2) Kualitas yang berkelanjutan, yang dilandasi kreatifitas,ingenuitas dan produktifitas pribadi sivitas akademika,dan dapat dirangsang oleh pola manajemen yang berasaskan otonomi.

3) Otonomi perguruan tinggi harus senafas dengan akuntabilitas mengenai penyelenggaran, kinerja dan hasil pergutuan tinggi.

4) Hak masyarakat untuk memperoleh informasi yang handal dan syahih mengenai penyelengaraan, kinerja dan hasil perguruan tinggi, diaktualisasi melalui proses akreditasi oleh Badan Akreditasi Nasional.

5) Tindakan manajerial utama yang melandasi pengambilan keputusan dan perencanaan di perguruan tinggi adalah proses evaluasi. ${ }^{3}$

${ }^{3}$ M Zainudin dan Susy Puspitasari, Strategi Pengembangan Pendidikan Tinggi : Implementasinya Terhadap Tugas dan Peranan Dosen, Buku Acuan Program Pekerti, (P2P Universitas Negeri Jakarta : 2006), h. 143 


\section{Implikasi Prinsip Relevansi dan Mutu}

Prinsip relevansi sebenarnya sepadan dengan konsep "link and match" di waktu lalu. Secara operasional,apa yang harus kita lakukan dalam rangka menerapkan konsep relevansi baik dalam proses manajemen pendidikan, pengembangan kurikulum, kegiatan perkuliahan, pengembangan dosen, penerimaan mahasiswa (leaner), sarana dan prasarana dan lain-lain. Dalam bidang perkuliahan misalnya bagaimana proses mendesain, melaksanakan dan mengevaluasi kegiatan perkuliahan? Apa peranan dosen dalam kegiatan perkuliahan agar dapat memberikan kontribusi secara optimal terhadap penerapan relevansi? Dua pertanyaan terakhir ini akan menjadi fokus bahasan tulisan ini.

\section{Peranan Dosen dalam Mendesain dan Melaksan- akan Perkuliahan}

Sehubungan dengan perubahan pada karakteristik model pembelajaran, maka harus juga dilakukan inovasi di dalam pola hubungan dosenmahasiswa. Pola directive harus diganti dengan non-directive. Dalam artian, peranan dosen yang terlalu dominan harus dirubah dengan menempatkan tanggung-jawab proses pembelajaran pada mahasiswa. Pendidikan yang tadinya lebih didasarkan pada mengingat, harus diganti dengan metode untuk mengembangkan kemampuan mahasiswa di dalam pengamatan, analisa, dan reasoning. Dengan pendekatan non-directive, mahasiswa akan lebih aktif dan dapat merangsang ekspresi mahasiswa sebebas-mungkin.

Kuliah tatap-muka hanyalah suatu pelengkap studi mahasiswa di dalam perpustakaan, laboratorium, atau di lapangan. Di sini, yang terpenting adalah peran dosen dalam membagikan dan mencangkokkan kesadaran, sikap, disiplin, dan etos ilmiah pada mahasiswa. Dengan lain perkataan, peran dosen adalah sebagai pembimbing dan rekan mahasiswa dalam mencari kebenaran ilmiah. Sehingga, tak kalah pentingnya adalah kemampuan dosen dalam merangsang hasrat ingin tahu mahasiswa. Karena, tanpa memiliki motivasi ingin tahu, segala usaha akan menjadi percuma.

Dalam merumuskan tujuan mata kuliah yang disebut Tujuan Instruksional Umum, dosen perlu mengidentifikasi kemampuan-kemampuan yang diharapkan dapat dicapai oleh mahasiswa pada akhir semester. Tujuan ini dijelaskan kepada maha- siswa berikut relevansinya dengan kebutuhan berbagai dunia kerja yang mungkin menjadi pekerjaan mereka nanti. ${ }^{4}$

Kemampuan dosen dalam merumuskan dan menjelaskan tujuan instruksional secara keseluruhan serta menjelaskannya secara menyakinkan kepada mahasiswa menjadi titik strategis pertama dari penerapan prinsip relevansi dalam pendidikan.

Dalam memilih dan menyajikan perkuliahan, disamping menghimpun atau menyusun bahan-bahan yang relevan dengan tujuan intruksional,dosen juga perlu mengembangkan contoh-contoh dan latihan penerapan konsep, prinsip, dan prosedur yang ada dalam bahan tersebut ke dalam berbagai dunia kerja yang mungkin menjadi pekerjaan mahasiswa setelah lulus nanti. Contoh-contoh dan latihan tersebut akan lebih mantap bila disajikan oleh dosen atau orang lain yang mempunyai pengalaman kerja dalam bidang tersebut.Pemberian contoh-contoh dan latihan tersebut menjadi titik strategis kedua dari penerapan prinsip relevansi.

Agar pelaksanaan pemberian contoh dan latihan ini berlangsung dengan mantap perlu dilakukan dengan berbagai cara sebagai berikut ini :

a. Dosen membawa mahasiswa ke dalam tempat / lingkungan kerja dan membahas jenis-jenis tugas yang sedang dikerjakan karyawan/pegawai yang merupakan penerapan dari konsep-konsep yang sedang dipelajari.

b. Dosen mengundang pembicara tamu yang mempunyai profesi dalam bidang pekerjaan yang sesuai dengan matakuliah yang sedang dipelajari mahasiswa.

c. Dosen (secara sendiri-sendiri atau melalui pengaturan dari perguruan tingginya) menciptakan kesempatan bagi mahasiswa untuk mencoba melakukan (berpraktek/magang) tugas seperti yang dikerjakan karyawan di lingkungan kerja tersebut. Kesempatan magang ini merupakan titik strategis ketiga dalam prinsip relevansi.

Untuk memperbesar kemungkinan pelaksanaan kesempatan tersebut, dosen perlu mempunyai pekerjaan sampingan (side job) dalam bidang pekerjaan yang relevan dengan matakuliah yang diajarkannya.Dengan mempunyai pekerjaan sampingan seperti itu, dosen akan lebih mantap dalam

${ }^{4} \mathrm{http}$ ://ayupgsduntan.blogspot.co.id/2014/06/tujuan-instruksionalpembelajaran.html. Diakses pada tanggal 2 Oktober 2017 
mengajar karena akan mampu memberikan contoh-contoh aplikasi dari teori yang ada dalam matakuliahnyake dalam dunia kerja.Pekerjaan sampingan ini merupakan titik strategis yang keempat dalam prinsip relevansi.

Proses perkuliahan yang baik harus dilengkapi dengan hal lain,yaitu penilaian terhadap proses dan hasil perkuliahan. Penilaian terhadap proses perkuliahan disamping bertujuan untuk memperbaiki perkuliahan dalam rangka meningkatkan efektifitas perkuliahan,juga bertujuan untuk meningkatkan motivasi mahasiswa dalam matakuliah tersebut. Oleh karena itu dosen perlu meminta bantuan mahasiswa dalam proses perkuliahan sebagai responden dan narasumber.

Dalam penilaian hasil perkuliahan,dosen perlu menentukan faktor - faktor yang dinilai dengan mengacu pada tujuan intruksional yang telah disusunnya. Rumusan tujuan instruksional harus direlevansikan dengan pekerjaan yang mungkin nanti akan dilakukan mahasiswa setelah lulus nanti. Dengan demikian,isi tugas,isi tes,atau ujian matakuliah ahrus pula relevan dengan pekerjaan tersebut. Disinilah letak titik strategis kelima dalam pinsip relevansi bagi dosen.

Kegiatan lain yang sangat membantu penerapan konsep relevansi adalah dosen menulis bahan matakuliah (paling sedikit mengkompilasi bahan kuliah) secara lengkap dan sistematis sehingga mahasiswa lebih mudah mempelajarinya dan dapat disesuaikan dengan waktu dan tempat yang tersedia baginya.

\section{Implikasi Akuntabilitas terhadap Tugas Dosen}

Konsepsi ini berkembang dari pendapat bahwa siapapun yang diserahi tugas mendidik harus dapat mempertanggungjawabkan tugasnya. Dalam konsepsi akuntabilitas paling sedikit ada empat komponen yang harus diperhatikan, yaitu tujuan, kegiatan, penilaian dan umpan balik. Tujuan dalam tiap usaha pendidikan harus dapat dirumuskan dengan jelas sehingga dapat diketahui dengan tepat misalnya banyaknya perubahan perilaku penampilan pada diri mahasiswa. Kegiatan yang dilakukan hendaknya merupakan kegiatan yang mengarah kepada tercapainya tujuan. Penilaian, merupakan usaha untuk mengetahui seberapa jauh tujuan telah tercapai serta berapa banyak biaya yang telah dikeluarkan.Sedang umpan balik dimaksudkan agar dapat dilakukan penyempurnaan, baik pada tujuan maupun kegiatan oleh mereka yang berkepentingan. Keempat komponen ini merupakan satu kesatuan, yang pada hakekatnya berada didalam suatu pendekatan.

Atas dasar konsepsi itu dapatlah dikatakan bahwa pendidikan yang akuntabel adalah pendidikan yang :

1. Tujuannnya jelas dan dapat dijabarkan menjadi tujuan - tujuan khusus.

2. Kegiatannnya dapat diawasi agar selalu mengarah kepada pencapaian tujuan.

3. Hasilnya efektif karena tujuan tercapai.

4. Proses pencapaian hasil itu efisien dengan mengingat sumber-sumber yang tersedia.

5. Menjalankan mekanisme umpan balik untuk menyempurnakan usaha pendidikan.

Para dosen sebagai pihak yang paling banyak mendapat sorotan mungkin berkeberatan terhadap pelaksanaan konsep akuntabilitas karena dari mereka dituntut kegiatan awal (persiapan) yang banyak, mengubah cara atau gaya yang telah dikuasai atau menjadi kebiasannya, serta merasa dicampuri, diawasi, dan dinilai kegiatan keahliannya.

\section{Pemerataan Pendidikan Tinggi}

Penyelenggara pendidikan tinggi bertanggungjawab melaksanakan kebijakan dalam meningkatkan pemerataan pendidikan tinggi yang meliputi tiga aspek berikut

a. Perluasan Kesempatan Belajar

Pemerataan kesempatan dalam memperoleh pendidikan tinggi berhubungan dengan peran pendidikan tinggi sebagai wahana mobilitas sosial.Pemerataan kesempatan mengikuti pendidikan tinggi berkenaan dengan dua segi yaiti kuantitatif dan kualitatif. Dari segi kuantitatif, hal ini mengangkut peningkatan kapasitas tampung program pendidikan S -1 dan Diploma di lembaga pendidikan tinggi negeri dan swasta. Dari segi kualitatif, harus diusahakan agar proporsi jumlah mahasiswa baik menurut bidang keahlian maupun jalur pendidikan sesuai dengan keperluan bidang dan jenjang keahlian dalam dunia kerja.

b. Penyebaran Pendidikan Tinggi melalui Pusat Pertumbuhan.

Pemerataan dalam penyebaran pendidikan 
25 被

tinggi secara geografis,terkait dengan peran pendidikan tinggi sebagai sumber daya pembangunan di wilayah kedudukannya.Penyebaran kemampuan menyelenggarakan fungsi kelembagaan pendidikan tinggi di semua wilayah, termasuk mengembangkan program- program unggul yang memiliki keberhasilan yang tinggi di suatu wilayah. Penyebaran kemampuan ini diselenggarakan antara lain melalui pusat-pusat pertumbuhan pendidikan tinggi di kawasan $\mathrm{Ba}-$ rat dan Timur Indonesia.

c. Peningkatan Peran Perguruan Tinggi dalam Menyiapkan Tenaga untuk Keperluan Setempat.

Perguruan tinggi harus mampu memenuhi kebutuhan sumberdaya setempat baik dalam jumlah maupun mutu dengan meningkatkan sumberdaya pendidikan untuk memasok kebutuhan sumberdaya manusia setempat, dan meningkatkan proses pendidikan di perguruan tinggi setempat dengan mengembangkan unsur-unsur pokok dan penunjang yang diperlukan.

\section{Kesimpulan}

Peningkatan kualitas pendidikan tinggi tidak terlepas dari kualitas sumberdaya manusia yang dimiliki. Oleh sebab itu peningkatan kualitas perilaku dan tingkah laku melalui jalur pendidikan perlu diupayakan. Selain itu juga adanya programprogram pelatihan yang efektif di perguruan tinggi untuk meningkatkan kemampuan anggota staf akademik dalam melaksanakan kegiatan fungsionalnya sangat dibutuhkan.

Dengan sumberdaya manusia yang berkualitas, diharapkan pendidikan tinggi akan menjadi lembaga yang mampu menghadapi tantangan masa depan dengan efektif.

\section{Daftar Pustaka}

Depdikbud, Ditjen Dikti. 1983 . Materi Dasar Pendidikan Program Akta Mengajar V Buku IIA. Dasar Ilmu Pendidikan. Jakarta : Depdikbud, Ditjen Dikti.

M Zainudin dan Susy Puspitasari, Strategi Pengembangan Pendidikan Tinggi : Implementasinya Terhadap Tugas dan Peranan Dosen, Buku Acuan Program Pekerti, P2P Universitas Negeri Jakarta : 2006

Mudyaharjo, R., Rasyidin, W., Soegiyanto, S. 1993 . Dasar-Dasar Kependidikan. Jakarta: Universitas Terbuka.

Soehendro, Bambang . 1996. Kerangka Pengembangan Pendidikan Tinggi Jangka Panjang 1996 2005. Jakarta : Depdikbud, Dirjen Dikti.

Suparman, Atwi.1994. Lima Titik Dasar dalam Penerapan Konsep Link and Match, Seminar Peran Perguruan Tinggi dalam Melaksanakan Keterkaitan dan Keterpaduan. Jakarta : Ditjen Dikti

Tamat, T. 1965. Dari Pedagogik ke Androgogik: Pedoman bagi PengelolaPendidikan dan Latihan. Jakarta: Pustaka Dian

Undang-Undang RI No.2 Tahun 1998 tentang Sistem Pendidikan Nasional

http://bsnp-indonesia.org/standar-nasional-pendidikan/ .Diakses pada tanggal 25 September 2017

http://ayupgsduntan.blogspot.co.id/2014/06/tujuan-instruksional-pembelajaran.html. Diakses $\begin{array}{llll}\text { pada tanggal } 2 & \text { Oktober } 2017\end{array}$ 
26 NUANSA Vol. XI, No. 1, Juni 2018

Ri zkan Syahbuddin | Upaya Peningkatan Mutu Pendidikan Tinggi 26 